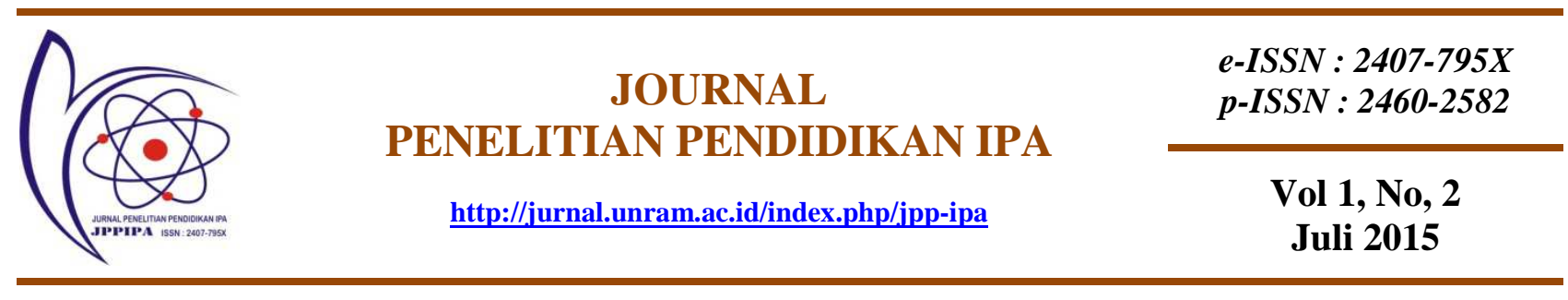

\title{
PENERAPAN PEMBELAJARAN DENGAN PENDEKATAN KETERAMPILAN PROSES SAINS UNTUK MENINGKATKAN HASIL BELAJAR KIMIA SISWA SMK NEGERI 3 MATARAM
}

\author{
Henikusniati $^{1}$, Yayuk Andayani ${ }^{2}$, Lalu Rudyat Telly $\mathbf{S}^{2}$ \\ Program Studi Magister Pendidikan IPA Program Pascasarjana Universitas Mataram ${ }^{123}$ \\ hkusniati@ymail.com
}

\begin{tabular}{|c|c|}
\hline Key Words & Abstract \\
\hline $\begin{array}{l}\text { Science process } \\
\text { skills, Learning } \\
\text { outcomes }\end{array}$ & $\begin{array}{l}\text { This study aims to determine the application of science process skills to improve } \\
\text { chemistry learning outcomes at SMK Negeri } 3 \text { Mataram. This study used a quasi- } \\
\text { experimental design with pre-test post-test control group design. Sampling was done } \\
\text { by using purposive sampling technique. The research sample for the experimental } \\
\text { class were } 37 \text { students and } 37 \text { students in the control class. Data were retreived using } \\
\text { multiple choice test that has been tested for its validity. Data were analyzed using } \\
\text { independent sample t-test at a significance level of } 0.05 \text {. N-Gain value calculation was } \\
\text { also used to determine the chemistry learning outcome. The result showed that value } \\
\text { of } N \text {-Gain in the experimental and control group were } 0,45 \text { and } 0,42 \text { respectively. The } \\
\text { results showed that the science process skills approach increased students learning } \\
\text { outcomes to medium category. The results of the t-test in both groups were shown not } \\
\text { to be significant }(\alpha=0.05) \text {. It can be concluded that there is no significant learning } \\
\text { outcomes improvement of experimental group in comparison to the control group }\end{array}$ \\
\hline
\end{tabular}

\begin{tabular}{ll}
\hline Kata Kunci & Abstrak \\
\cline { 2 - 4 } $\begin{array}{l}\text { Keterampilan } \\
\text { proses sains, }\end{array}$ & Penelitian ini bertujuan untuk mengetahui penerapan pembelajaran dengan \\
Hasil belajar & Nendekatan keterampilan proses sains untuk meningkatkan hasil belajar kimia di SMK \\
& desain pre-test post-test control group design. Pengambilan sampel dilakukan dengan \\
& menggunakan teknik purposive sampling. Sampel penelitian untuk kelas eksperimen \\
& berjumlah 37 siswa dan 37 siswa untuk kelas kontrol. Pengambilan data \\
& menggunakan instrumen tes hasil belajar berbentuk pilihan ganda yang telah diuji \\
& validitasnya. Pengujian statistik dengan menggunakan independent sample t-test yang \\
& telah melalui tahap uji normalitas dan uji homogenitas pada taraf signifikan 0,05. \\
& Analisis data dilengkapi dengan perhitungan nilai N-Gain untuk mengetahui \\
& peningkatan hasil belajar kimia. Hasil analisis data menunjukkan bahwa nilai N-Gain \\
& pada kelas eksperimen sebesar 0,45 dan kelas kontrol sebesar 0,42, hasil penelitian \\
& menunjukkan bahwa keterampilan proses sains siswa mengalami peningkatan dengan \\
& kategori sedang. Hasil uji-t pada kedua gain kelompok menunjukkan hasil yang tidak \\
& berbeda secara signifikan ( $\alpha=0,05)$. Dari hasil penelitian yang diperoleh, bahwa tidak \\
& ada perbedaan peningkatan hasil belajar siswa secara signifikan antara kelas \\
& eksperimen dengan kelas kontrol.
\end{tabular}




\section{PENDAHULUAN}

Sains merupakan mata pelajaran yang diarahkan untuk mencari tahu dan berbuat sehingga dapat membantu siswa untuk memperoleh pemahaman yang lebih mendalam tentang alam sekitar. Pembelajaran merupakan proses interaksi peserta didik dengan pendidik dan sumber belajar pada suatu lingkungan belajar, sedangkan model pembelajaran adalah suatu perencanaan atau suatu pola yang digunakan sebagai pedoman dalam merencanakan pembelajaran di kelas atau pembelajaran dalam tutorial (Rosidi, 2015). Ketepatan penggunaan model pembelajaran dalam suatu kelas tentu akan mempengaruhi hasil belajar siswa di kelas tersebut.

Pendekatan keterampilan proses adalah suatu pendekatan pengajaran yang memberi kesempatan kepada siswa untuk memahami proses penemuan atau penyusunan suatu konsep sebagai keterampilan proses sains. Seorang pendidik, berupaya untuk meningkatkan kualitas pengetahuan siswa, sehingga dapat mengusai suatu pembelajaran menjadi lebih bermakna, untuk dapat meningkatkan hasil belajar siswa sesuai dengan tujuan pembelajaran yang ditetapkan oleh kurikulum 2013. Kurikulum 2013 bertujuan untuk mempersiapkan manusia indonesia agar memiliki kemampuan hidup sebagai pribadi dan warga negara yang beriman, produktif, kreatif, inovatif, serta mampu berkontribusi dalam kehidupan bermasyarakat, berbangsa, bernegara (Depdikbud, 2013).

Menurut Jumiati (2011), Keterampilan proses itu sendiri melibatkan keterampilan pengetahuan atau intelektual, keterampilan intektual memicu siswa agar dapat memahami materi yang disampaikan oleh guru pada proses kegiatan belajar mengajar. Dalam pelaksanaan kegiatan belajar mengajar kimia, hendaknya menggunakan strategi yang melibatkan siswa aktif dalam belajar baik secara mental, fisik maupun sosial.

Studi pendahuluan di SMK Negeri 3 Mataram dilakukan pada tanggal 7 Oktober 2014, dengan menyebarkan angket kepada siswa kelas XI dan guru kimia yang mengajar di kelas XI program keahlian teknik bangunan. Berdasarkan hasil analisis angket siswa, terdapat $71,42 \%$ siswa menyatakan tidak pernah dibimbing untuk melakukan perumuskan hipotesis. Sebanyak 76,19\% siswa menyatakan guru tidak pernah melakukan eksperimen sehingga proses pembelajaran di kelas belum mengarah pada pendekatan keterampilan proses sains. Model pembelajaran cenderung berpusat pada guru, sehingga sebagian besar siswa cenderung bersikap pasif. Menurut Deta dalam Nur (2013), siswa yang memiliki keterampilan proses tinggi akan mudah dalam melakukan penyelidikan dalam metode pembelajarannya. Keterampilan proses yang meliputi keterampilan proses dasar, 
keterampilan pengukuran dan perhitungan, keterampilan perencanaan eksperimen, dan keterampilan mengolah serta menyajikan data.

Berdasarkan latar belakang di atas, peneliti berusaha untuk menggali lebih lanjut penerapan pendekatan keterampilan sains dalam proses pembelajaran yang berjudul "penerapan pembelajaran dengan pendekatan keterampilan proses sains untuk meningkatkan hasil belajar kimia siswa di SMK Negeri 3 Mataram".

\section{METODE PENELITIAN}

Subyek penelitian ini adalah siswa SMK Negeri 3 Mataram kelas XI program keahlian teknik bangunan semester 3 (ganjil) tahun pelajaran 2014/2015. Jenis penelitian yang digunakan pada penelitian ini adalah penelitian eksperimen semu dengan desain nonequivalent pre-test pos-ttest control group design. Populasi dalam penelitian ini adalah program keahlian teknik bangunan kelas XI SMK Negeri 3 Mataram yang berjumlah 137 siswa. Sampel yang diambil adalah 2 kelas yaitu kelas eksperimen diberikan perlakuan menggunakan model pembelajaran pendekatan keterampilan proses sains dan kelas kontrol diberikan perlakuan model pembelajaran pendekatan konvensional. Teknik pengambilan sampel secara purposive sampling.

Instrumen yang digunakan dalam penelitian ini adalah instrumen tes, untuk mengukur aspek pengetahuan (kognitif) siswa dalam bentuk soal pilihan ganda. Instrumen yang telah diuji validitas, yang berjumlah 30 soal. Teknik analisis data menggunakan teknik statistik uji-t memerlukan prasyarat yang harus dipenuhi, antara lain normalitas data dan homogenitas. Untuk melihat peningkatan hasil belajar pre-test dan post-test digunakan uji $N$-Gain. Uji normalitas dilakukan dengan menggunakan statistik uji Kolmogorove-Smirnov dan Uji homogenitas menggunakan uji homogenitas varian.

\section{HASIL DAN PEMBAHASAN}

Untuk mengetahui peningkatan hasil belajar maka dilakukan analisis $N$-Gain. Uji Gain digunakan untuk mengetahui peningkatan hasil belajar ranah pengetahuan berdasarkan nilai pre-test dan post-test dengan rumus gain adalah sebagai berikut:

$$
N-\text { gain }=\frac{\text { Skor Posttest }- \text { Skor Prestest }}{\text { Skor Maksimum }- \text { Skor Prestest }}
$$


Keterangan:

Skor Pre-test: skor tes awal siswa

Skor Post-test: skor tes akhir siswa

Skor Maksimum: skor maksimal

Kriteria $N$-Gain: $\mathrm{N}$-gain $\geq 0,7$ (tinggi); 0,7 > N-gain $\geq 0,3$ (sedang); N-gain $<0,3$ (rendah) (Meltzer dalam Rosidi, 2015).

Tabel 1. Hasil Nilai N-Gain Hasil Belajar

\begin{tabular}{|c|c|c|c|}
\hline \multirow{2}{*}{ No } & \multirow{2}{*}{ Aspek } & \multicolumn{2}{|c|}{$N$-Gain } \\
\cline { 3 - 4 } & & Kelas Eksperimen & $\begin{array}{c}\text { Kelas } \\
\text { Kontrol }\end{array}$ \\
\hline 1 & Jumlah siswa & 37 & 37 \\
\hline 2 & Nilai tertinggi & 0,66 & 0,63 \\
\hline 3 & Nilai terendah & 0,06 & 0,17 \\
\hline 4 & Nilai rata-rata & 0,45 & 0,42 \\
\hline
\end{tabular}

a. Uji normalitas

Berdasarkan taraf signifikan 5\% diperoleh nilai signifikansi sebesar 0,200 pada kelas kontrol sedangkan pada kelas eksperimen 0,073. Harga signifikan kedua kelas tersebut lebih besar dari 0,05 ( $>00,05)$ sehingga dapat disimpulkan bahwa data kedua kelas tersebut berdistribusi normal.

b. Uji Homogenitas

Berdasarkan taraf siginifikan 5\% diperoleh nilai signifikansi sebesar 0,062. Harga signifikan tersebut lebih besar dari 0,05 (p>0,05) sehingga dapat disimpulkan bahwa data $N$-Gain kelas eksperimen dan kelas kontrol homogen.

c. Uji Hipotesis

Data nilai $N$-Gain hasil belajar yang berdistribusi normal dan homongen, selanjutnya dilakukan uji hpotesis dengan uji-t. Hasil analisis uji-t ditampilkan pada Tabel 2.

Tabel 2. Hasil Uji-t N-Gain Hasil Belajar

\begin{tabular}{|c|c|c|c|}
\hline \multirow{2}{*}{} & \multicolumn{3}{|c|}{ Uji-t (uji beda rata-rata) } \\
\cline { 2 - 4 } & $\mathrm{t}$ & $\mathrm{df}$ & Sig. \\
\hline N-Gain Hasil Belajar & 1,182 & 72 &, 241 \\
\hline
\end{tabular}

Berdasarkan taraf siginifikan 5\% diperoleh nilai signifikan sebesar 0,241. Harga signifikan tersebut lebih besar dari 0,05 $(p>0,05)$ sehingga dapat dikatakan 
bahwa tidak ada perbedaan peningkatan hasil belajar antara kelas eksperimen dan kelas kontrol.

Keterampilan proses sains mengacu pada beberapa indikator meliputi mengamati, mengajukan pertanyaan, menyususn hipotesis, melakukan eksperimen dan menyimpulkan (Ambarsari, 2013). Hasil belajar tergantung dari penguasaan siswa terhadap materi atau kemampuan kognitif. Adapun materi pokok dalam pembelajaran kimia adalah larutan elektrolit dan larutan non-elektrolit. Berdasarkan hasil analisis data pre-test dan post-test, kelas eksprimen memiliki nilai rata-rata pre-test dan posttest lebih tinggi dibandingkan kelas kontrol. Kelas eksperimen memperoleh nilai ratarata pre-test sebesar 38,00 sedangkan kelas kontrol memiliki nilai rata-rata 32,77. Adapun hasil nilai rata-rata post-test kelas eksperimen memperoleh nilai rata-rata 66,51 se dangkan kelas kontrol nilai rata-ratanya 61,16. Jika dilihat dari perolehan nilai pre-test dan post-test kedua kelas, maka kelas eksperimen mempunyai nilai lebih tinggi dari pada nilai kelas kontrol.

Berdasarkan perolehan nilai $N$-Gain, kelas eksperimen memiliki rata-rata sebesar 0,45, sedangkan pada kelas kontrol memiliki rata-rata sebesar 0,42. Hasil penelitian ini menunjukkan bahwa dengan menggunakan metode pendekatan keterampilan proses sains dan konvensional, bisa menunjukkan peningkatan, walaupun masih dalam kategori sedang. Apabila dilihat dari hasil pre-test dan posttest, peningkatan hasil belajar kelas eksperimen sebesar 45\%, sedangkan kelas kontrol sebesar $42 \%$. Hasil tersebut, menunjukkan bahwa ada peningkatan hasil belajar siswa. Hasil penelitian Rahayu (2011), menunjukkan bahwa dengan pendekatan keterampilan proses sains dapat meningkatkan hasil belajar siswa. Hasil yang sama juga ditunjukkan oleh Deta (2013), yaitu dengan penerapan pendekatan keterampilan proses sains dapat meningkatkan hasil belajar siswa.

Hasil penelitian menunjukkan bahwa penerapan pembelajaran dengan pendekatan keterampilan proses sains, masih belum bisa meningkatkan hasil belajar siswa SMK secara siginifikan pada taraf yang lebih tinggi. Hal tersebut disebabkan karena beberapa faktor, menurut Sukma (2012), (1) kurangnya perhatian siswa untuk belajar, hal ini terbukti ketika kegiatan pembelajaran berlangsung di kelas terlihat bahwa partisipasi siswa masih rendah. Hal ini didukung oleh pernyataan Rosidi (2015), bahwa salah satu persyaratan pendukung dalam menerapkan model pembelajaran pendekatan keterampilan proses sains adalah siswa perlu memiliki 
kecerdasan/kecakapan awal yang baik. (2) siswa masih kurang dalam membaca literatur atau mencari informasi, hal tersebut kemungkinan dikarenakan siswa yang kurang dibiasakan dalam membaca. (3) pembelajaran yang berjalan singkat. Hai ini didukung oleh pernyataan (Resti, 2010), untuk mendapatkan hasil yang maksimal maka melatihkan keterampilan proses sains melalui keterampilan proses dasar dan keterampilan proses terintegrasi, agar siswa memperoleh hasil belajar yang lebih baik. (4) kemampuan awal. Hal ini didukung oleh pernyataan Praptiwi (2012), kemampuan awal akan mempengaruhi berhasil atau tidaknya seorang siswa dalam pembelajaran. Jika kemampuan awal siswa baik, maka siswapun akan memperoleh hasil yang baik. (5) Pengelolaan kelas. Hal ini didukung oleh Prasetiyo (2013), perlunya perhatian terhadap pengelolaan kelas selama proses pembelajaran berlangsung, hal ini bertujuan untuk mengefektifkan waktu yang sangat terbatas pada saat proses pembelajaran.

Belum adanya kesiapan siswa menggunakan model pendekatan keterampilan proses sains, membuat siswa cukup mengalami kesulitan selama proses pembelajaran, yaitu dapat terlihat dari proses diskusi kelompok dan presentasi. Hal ini didukung oleh pernyataan Resti, (2010) bahwa kesiapan siswa menerima suatu materi akan sangat berpengaruh dengan tingkat pemahaman siswa. Hasil uji-t terhadap nilai $N$-Gain hasil belajar menunjukkan tidak ada perbedaan peningkatan secara signifikansi antara siswa kelas eksperimen dan kelas kontrol.

\section{KESIMPULAN}

Berdasarkan hasil penelitian yang telah dilakukan, kesimpulan yang diperoleh adalah ada peningkatan keterampilan proses sains siswa dilihat dari hasil perhitungan $N$-Gain yaitu kelas eksperimen sebesar 0,45 dan kelas kontrol sebesar 0,42, hasil penelitian menunjukkan bahwa keterampilan proses sains siswa mengalami peningkatan dengan kategori sedang. Sehingga tidak ada perbedaan peningkatan hasil belajar siswa secara signifikan antara kelas eksperimen dan kelas kontrol.

\section{DAFTRA PUSTAKA}

Arikunto, S., 2013. Dasar-Dasar Evaluasi Pendidikan. Jakarta: Bumi Aksara.

Deta, V.A. Suparmi, dan Widha, S. 2013. Pengaruh Metode Inkuiri Terbimbing dan Proyek, Kreativitas, serta Keterampilan Proses Sains Terhadap Prestasi Belajar Siswa. Jurnal Pendidikan Fisika Indonesia. ISSN: 1693-1246 Vol. 9 No.1 ( 2834). 
Jufri, A. W. 2010. Belajar dan Pembelajaran Sains. Lombok: Arga Puji Press.

Nana, S. 2009. Penilaian Hasil Proses Belajar Mengajar. Bandung: PT Remaja Rosdakarya.

Lutfa, A., Sugianto, dan Sulhadi. 2014. Penerapan Model Pembelajaran PBL (Problem Based Learning) untuk Menumbuhkan Keterampilan Proses Sains pada Siswa SMA. Semarang: Physics Education Journal. UPEJ 3 (2).

Purnamawati, Dsk. Kt. Ardana, I Kt. dan Manuaba, IBS. 2014. Pengaruh Pendekatan Keterampilan Proses Menggunakan Media Kongkret Terhadap Hasil Belajar IPA Siswa Kelas V Sd Gugus 3 Kecamatan Tampaksiring: e-Journal PGSD. Vol.2 No.1 (38-42).

Purwanto, 2010. Evaluasi Hasil Belajar. Yogyakarta: Pustaka Pelajar.

Pragogi, P. Asy'ari, M. Sukaisih, R. dan Hidayat, S. 2014. Keterampilan Proses Sains. Lombok NTB: Duta Pustaka Ilmu.

Rahayu, E. Susanto, H. dan Yulianti, D. 2011. Pembelajaran Sains dengan Pendekatan Keterampilan Proses untuk Meningkatkan Hasil Belajar dan Kemampuan berpikir Kreatif Siswa. Jurnal Pendidikan Fisika Indonesia. Vol.7 No. 1 (3337).

Sriyani, Niawati, I. 2010. Kimia untuk SMK-Teknik. Surakarta: Hayati Tumbuh Subur.

Wardani, S. Widodo, A.T. Priyani, N. E. 2009. Peningkatan Hasil Belajar Siswa Melalui Pendekatan Keterampilan Proses Sains Berorientasi Problem-Based Instruction. Jurnal Inovasi Pendidikan Kimia. Vol.3 No.1 (391-399).

Yokhebed, Sudarisma, S. dan Sunarno, W. 2012. Pembelajaran Biologi menggunakan Model Pembelajaran Berbasis Masalah dengan Pendekatan Keterampilan Proses Sains untuk Meningkatkan Motivasi Belajar dan Hasil Belajar. Jurnal inkuiri. Vol.1 No.3 (183-194) http://jurnal.pasca.uns.ac.id.

Yuniastuti, E. 2013. Upaya Meningkatkan Keterampilan Proses dan Hasil Belajar Biologi dengan Pendekatan Pembelajaran Jelajah Alam Sekitar pada Siswa Kelas VII SMP Kartika V-1 Balikpapan. Jurnal Socioscientia. Vol.5 No.1 (31-38). 